\title{
Reduction of Cyclic and Linear Organic Carbonates using a Readily Available Magnesium Catalyst
}

\author{
Marcin Szewczyk, ${ }^{\dagger}$ Marc Magre $^{\dagger}$ Viktoriia Zubar, $^{\dagger}$ and Magnus Rueping ${ }^{\star, \dagger, \ddagger}$ \\ ${ }^{\dagger}$ Institute of Organic Chemistry, RWTH Aachen University, Landoltweg 1, 52074 Aachen, Germany \\ ${ }^{\ddagger}$ KAUST Catalysis Center (KCC), King Abdullah University of Science and Technology (KAUST), Thuwal 23955- \\ 690o, Saudi Arabia
}

\begin{abstract}
The efficient reduction of cyclic and linear organic carbonates catalyzed by a readily available earth alkaline catalyst has been achieved. The described homogenous reaction based on a ligand-free magnesium catalyst provides an indirect route for the conversion of $\mathrm{CO}_{2}$ into valuable alcohols. The reaction proceeds with high yields under mild reactions conditions, with low catalyst loading, short reaction times and shows a broad applicability towards various linear and cyclic carbonates and can additionally be applied for the depolymerization of polycarbonates.
\end{abstract}

KEYWORDS: magnesium, carbonates, hydroboration, carbon dioxide, alkaline base earth-abundant metal

Recent years have shown progress in the application of carbon dioxide as a $C_{1}$ building block. ${ }^{\left[{ }^{[}\right]}$One of the industrially applied approaches for reduction of atmospheric $\mathrm{CO}_{2}$ emissions is the use of this Greenhouse gas in reactions with alcohols or epoxides to form organic carbonates. Especially the latter method is based on an economic and environmental rationale as not only it provides commercially important chemicals but also utilizes readily available epoxides. ${ }^{[2]}$ The following reduction of organic carbonates results a two-step route conversion of $\mathrm{CO}_{2}$ into methanol and value-added diols or their derivatives.

However, reduction of organic carbonates is disfavored due to their high stability. Therefore, organic carbonates can be used as solvents, even in reductive transformations involving metal hydride species. ${ }^{[3]}$ For this reason only few examples of carbonate reductions have been reported to date. ${ }^{[4,5]}$ Direct hydrogenation, the most common method for the reduction of carbonates has been studied in the past. However, all protocols are based on transition-metal catalysts and often require high pressures and temperatures. ${ }^{[4]}$

Boranes are often used as alternative reducing agents in order to circumvent high-pressure hydrogenations with use of the flammable hydrogen gas. Thus, the hydroboration of carbonates is an interesting alternative. Recently, Leitner and co-workers reported an interesting transition metal catalyzed reduction of organic carbonates using pinacolborane as reducing agent. ${ }^{[.]}$However, an efficient transition metal-free protocols based on earth alkaline metals remain an elusive goal. Thus, the use of a readily available magnesium catalyst which could be used in low catalyst loadings for the reduction of $\mathrm{CO}_{2}$ derived organic carbonates to value added alcohols would be an important advancement in achieving the requirements of an ecologically and economically benign process (Scheme 1).

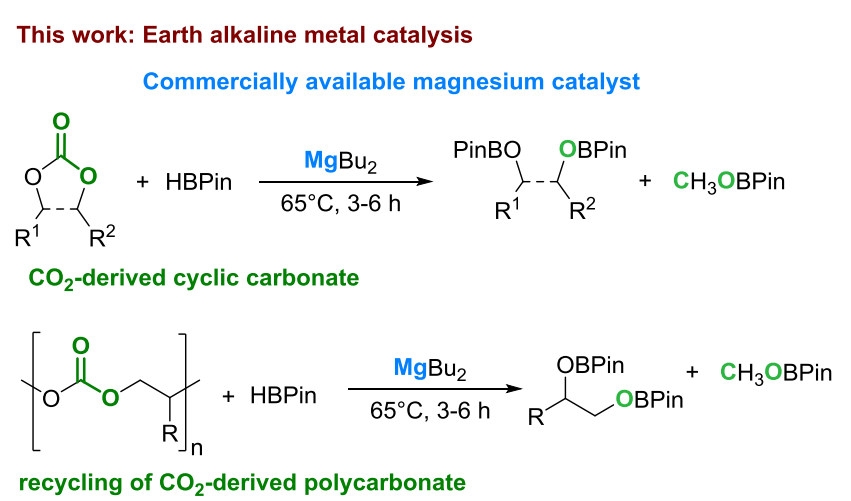

Scheme 1. $\mathrm{MgBu}_{2}$-catalyzed chemoselective hydroboration of ketones.

Furthermore, the successful development of such a process may also be extended to the recycling of polycarbonates with the simultaneous formation of valuable diols and methanol. Based on our interest in earth alkaline metal catalysis and in particular magnesium catalysis we wondered whether a readily available magnesium catalyst could be applied in the reduction of $\mathrm{CO}_{2}$ derived carbonates.

Although magnesium is one of the most abundant metals on earth, the application of magnesium-based catalysts for organic reactions is still relatively unexplored compared with other metals. ${ }^{[6-8]}$ Recently, magnesium complexes, such as $\beta$-diketiminato-magnesium complexes, ${ }^{[9,10]}$ have been employed for the hydroboration of unsaturated polarized bonds, including adehydes, ketones and esters. ${ }^{[1-13]}$ Our group reported a protocol for the selective hydroboration of terminal and internal alkynes catalyzed by commercially available $\mathrm{MgBu}_{2}$. ${ }^{[1 \mathrm{a}]}$ Mechanistic studies revealed that in the presence of the reductant HBPin, an active BuMgH species is formed in situ. ${ }^{[14]}$ Giv- 
en the growing interest in earth alkaline metal-catalyzed organic transformations and the valorization of $\mathrm{CO}_{2}$ and its derivatives, we decided to examine a $\mathrm{Mg}$-catalyzed reduction of carbonates as well as the extension to the recycling of polycarbonates with simultaneous generation of valuable diols and methanol (Scheme 1).

To develop a practical reduction protocol for the rather stable and challenging cyclic carbonates we started to explore a magnesium catalyzed protocol which should proceed with low catalyst loading and under mild reaction conditions. Hence we chose cyclic carbonate ra as our model substrate and run initial screening of solvents, as well as in solvent-free conditions, at ambient temperature (Table 1 , entries 1-4). Analysis of the crude reaction mixture by ${ }^{1} \mathrm{H}$ NMR spectroscopy revealed that $2 \mathrm{a}$ and MeOBPin were the only products formed during the reaction. However, under these conditions the reactions were not complete within 4 hours and significant amounts of carbonate were still present in the crude mixtures. Further optimization was carried out with toluene as a solvent. Increasing the reaction temperature allowed to achieve full conversion (Table 1 , entry 5). Furthermore, we decided to lower the amount of the catalyst (Table 1, entries 6-7) and thus the optimal catalyst loading of $3 \mathrm{~mol} \%$ was established. It is worth to mention that use of a $\beta$ diketiminate-MgBu complex I also provided the product; however lower yield was observed (entry 8 vs. 9). In the absence of the catalyst no conversion of 1a was observed (Table 1, entry 10).

Table 1. Optimization of $\mathrm{MgBu}_{2}$-catalyzed hydroboration of carbonate 1a. ${ }^{[a]}$

\begin{tabular}{|c|c|c|c|c|c|}
\hline 익 & \multicolumn{2}{|c|}{$\begin{array}{c}\mathrm{MgBu}_{2} \text { (cat.) } \\
\text { HBPin ( } 3.1 \text { equiv }\end{array}$} & \multicolumn{2}{|c|}{ inBO OBPin } & ${ }_{3} \mathrm{OBP}$ in \\
\hline 1a & \multicolumn{5}{|c|}{$2 a$} \\
\hline Entry & Solvent & $\begin{array}{l}\text { Cat. } \\
(\%)\end{array}$ & $\begin{array}{l}\text { Temp. } \\
\left({ }^{\circ} \mathrm{C}\right)\end{array}$ & $\begin{array}{l}\text { Time } \\
\text { (h) }\end{array}$ & $\begin{array}{l}\text { Yield } \\
(\%)^{[b]}\end{array}$ \\
\hline 1 & Toluene- $d_{8}$ & 5 & 23 & 4 & 78 \\
\hline 2 & THF- $\mathrm{d}_{8}$ & 5 & 23 & 4 & 52 \\
\hline 3 & Benzene- $d_{6}$ & 5 & 23 & 4 & 81 \\
\hline 4 & Neat & 5 & 23 & 4 & 71 \\
\hline 5 & Toluene- $\mathrm{d}_{8}$ & 5 & 65 & 3 & $>95$ \\
\hline 6 & Toluene- $d_{8}$ & 3 & 65 & 3 & $>95$ \\
\hline 7 & Toluene- $d_{8}$ & 2 & 65 & 3 & 88 \\
\hline 8 & Toluene- $\mathrm{d}_{8}$ & 3 & 65 & 2 & 92 \\
\hline $9^{[c]}$ & Toluene- $d_{8}$ & 3 & 65 & 2 & 82 \\
\hline 10 & Toluene- $d_{8}$ & - & 65 & 3 & $<5$ \\
\hline
\end{tabular}

[a] $1 \mathrm{a}(1 \mathrm{mmol}), \mathrm{HBpin}$ (3.1 equiv), MgBu2 (2-5 mol\%, 0.5 $\mathrm{M}$ in heptane), solvent [1 M] at given temperature. [b] Determined by ${ }^{1} \mathrm{H}$ NMR using 1,3,5-trimethoxybenzene as internal standard. [c] With $\beta$-diketiminate-MgBu I.

Under the optimized reaction conditions, we investigated the scope and limitations of this transformation. In general, excellent yields were obtained (Table 2). Ethylene carbonate (1b) and its derivatives bearing aliphatic substituents, such as Me (1c), Et (1d), n-Hex (1e) and even sterically hindered $t$-Bu (1f), were efficiently reduced with excellent yields within 3 hours. Hydroboration of glycerol derivatives with methyl (1/h) and benzyl (1i) as protecting groups, as well as free $\mathrm{OH}$ group (1g) resulted in the formation of the desired products. Chemoselective reduction of unsaturated carbonate (1j) was also possible and no product of reduction of $\mathrm{C}-\mathrm{C}$ double bond was observed. Cyclic cis- and trans-diol derivatives (2k and $\mathbf{2 l}$, respectively) were obtained with excellent yields regardless of the stereochemistry of the starting material. Sixmembered ring organic carbonates also underwent efficient hydroboration, affording the corresponding 1,3-diol derivatives (2m-2p) bearing various alkyl and aryl substituents. The lower activity observed in the case of 1,3dioxan-2-one ( $\mathbf{1 m}$ ) can be attributed to the lower solubility of the starting material.

Linear carbonates, especially aliphatic ones, usually require harsher conditions in order to achieve good conversions. ${ }^{[15]}$ To our delight, by simply prolonging the reaction time to 4 hours, we were able to reduce methyl, ethyl and benzyl carbonates (1q-1s) with full conversions and excellent yields. Phenol-derived carbonates, both cyclic and linear $(\mathbf{t t}, \mathbf{1 u})$, required elevated temperature to yield the corresponding products in $90-92 \%$ yield. Further exploration focused on the depolymerization of polycarbonates. Polypropylene carbonate (PPC, 1v) which can be made from propylene and $\mathrm{CO}_{2}$, smoothly underwent hydroboration in the presence of the magnesium catalyst. In general, we were delighted to see that our earth alkaline metal catalyst based on low-cost and commercially available $\mathrm{MgBu}_{2}$ competes favorably with existing protocols in terms of broader substrate scope and milder reaction conditions. To demonstrate the practical applicability of the developed reaction, a gram-scale reduction of carbonate 19 was carried out (Scheme 2). After hydrolysis in acidic conditions, we obtained the deprotected alcohol 3 in $82 \%$ yield. ${ }^{[16]}$

The $\mathrm{MgBu}_{2}-\mathrm{HBpin}$ catalytic system has been also tested for the reduction of $\mathrm{CO}_{2}$ (Scheme 3$)$. In this case, elevated temperature and $10 \mathrm{~mol} \%$ of the catalyst were necessary for the full consumption of HBPin, leading exclusively to BPin-protected methanol derivative. ${ }^{[16,17]}$

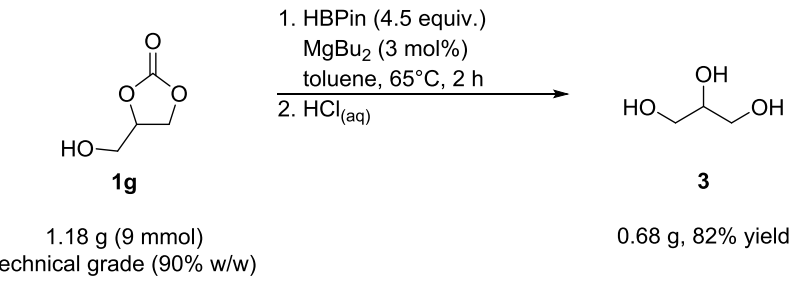

Scheme 2. Large-scale transformation.

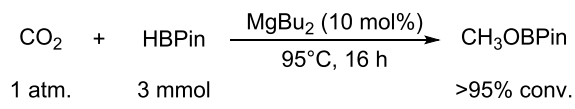

Scheme 3. $\mathrm{MgBu}_{2}$-catalyzed hydroboration of $\mathrm{CO}_{2}$. 
Table 2. Magnesium-catalyzed hydroboration of $\mathrm{CO}_{2}$-derived carbonates. ${ }^{[a]}$

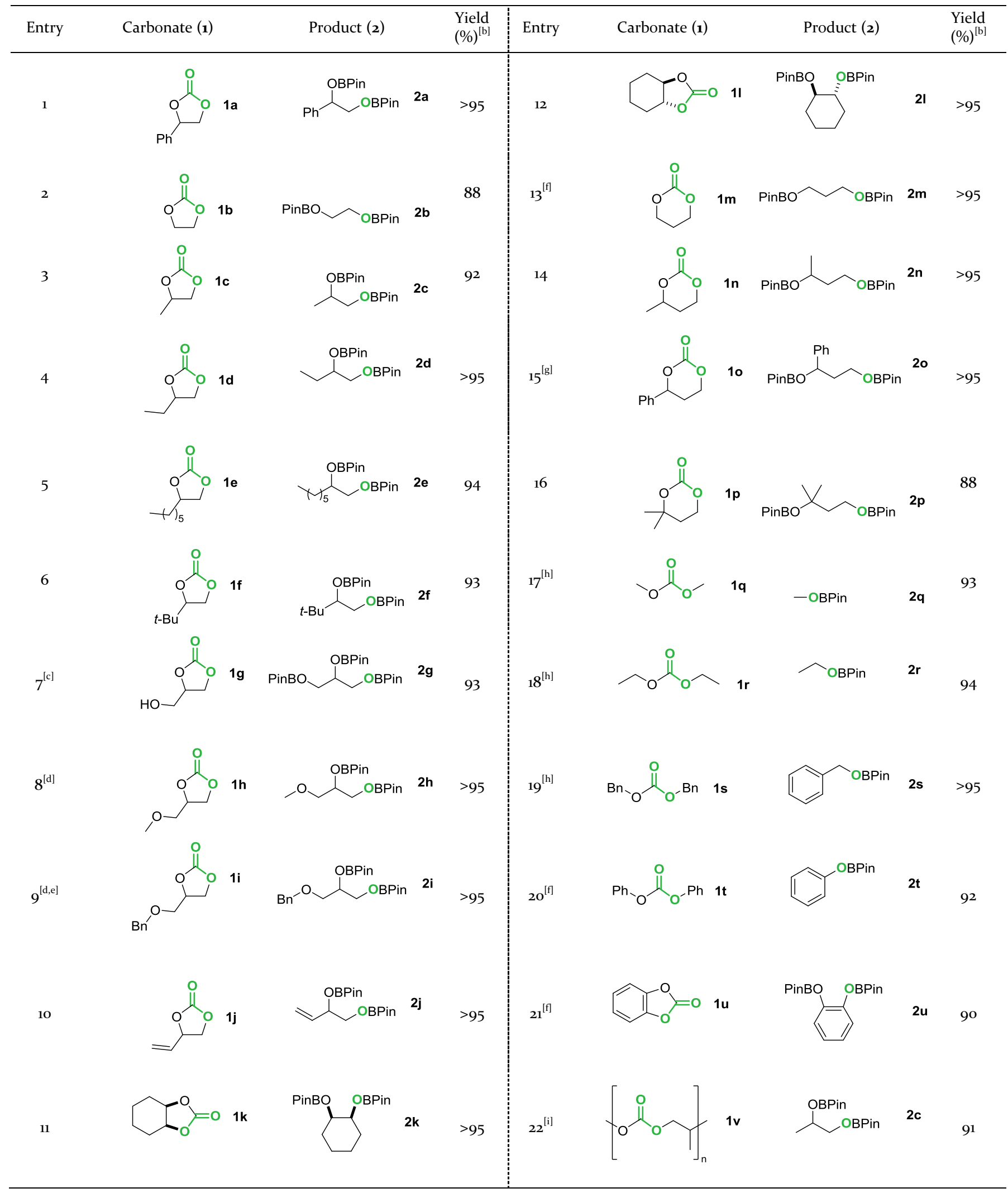

[a] 1 ( $1 \mathrm{mmol}$ ), HBpin (3.1 equiv), $\mathrm{MgBu}_{2}\left(3 \mathrm{~mol} \%\right.$, o.5 $\mathrm{M}$ in heptane), solvent $[1 \mathrm{M}]$ at $65^{\circ} \mathrm{C}$ for $3 \mathrm{~h}$. [b] Determined by ${ }^{1} \mathrm{H} N M R$ using 1,3,5-trimethoxybenzene as internal standard. [c] 4 equiv. of HBPin were used. [d] Mesitylene was used as an internal standard. [e] Reaction time $8 \mathrm{~h}$. [f] Reaction time $6 \mathrm{~h}$ at $85^{\circ} \mathrm{C}$. [g] $\mathrm{C}_{6} \mathrm{D}_{6}$ was used as a solvent. [h] Reaction time $4 \mathrm{~h}$. [i] Average $\mathrm{M}_{\mathrm{n}}$ of starting material: $\sim 50,000$. 
a) Formation of BuMgH active species

\begin{tabular}{|c|c|c|c|c|c|}
\hline $\mathrm{MgBu}_{2}$ & + & HBPin & $\frac{\text { toluene- }_{8}}{65^{\circ} \mathrm{C}}$ & $\mathrm{BuMgH}$ & + BuBPin \\
\hline & & & & & $\begin{array}{l}\text { Detected by } \\
{ }^{11} \mathrm{~B} \text { NMR }\end{array}$ \\
\hline
\end{tabular}

b) Reduction of plausible intermediate

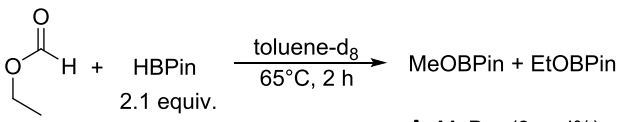

A. $\mathrm{MgBu}_{2}(3 \mathrm{~mol} \%)$ : >95\% conv

c) Competing reaction rate of equimolar mixture of carbonate and formate

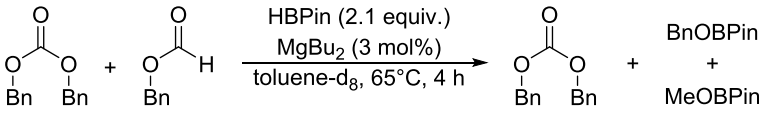

$$
\begin{aligned}
& 1 \mathrm{~s} \\
& 5 \\
& \begin{array}{l}
\text { 1s } \\
>95 \% \text { recovery }>95 \% \text { conv. }
\end{array}
\end{aligned}
$$

Scheme 4. Control experiments for mechanistic studies.

In agreement with the previous study, reaction of $\mathrm{MgBu}_{2}$ with $\mathrm{HBPin}$ gives the active species $\mathrm{BuMgH}$, alongside with BuBPin (Scheme 4a). ${ }^{[11 a]}$ For the better understanding of the reaction mechanism, we conducted several additional control experiments. We reasoned that the hydroboration of carbonates proceeds in three separated catalytic cycles with the corresponding formate and formaldehyde as intermediates. When the reaction with the plausible intermediate formate $\mathbf{4}$ was carried out (Scheme $4 \mathrm{~b}$ ), we found that only in the presence of the Mg-catalyst the reduction was possible, meaning that each catalytic step requires the presence of the magnesium catalyst. Finally, when an equimolar mixture of carbonate $1 \mathrm{~s}$ and formate $\mathbf{5}$ were tested in a competitive reaction, we found out that only the formate $\mathbf{5}$ was reduced quantitatively, whereas the carbonate is remained unreacted (Scheme 4c). With this finding, we reasoned

a)

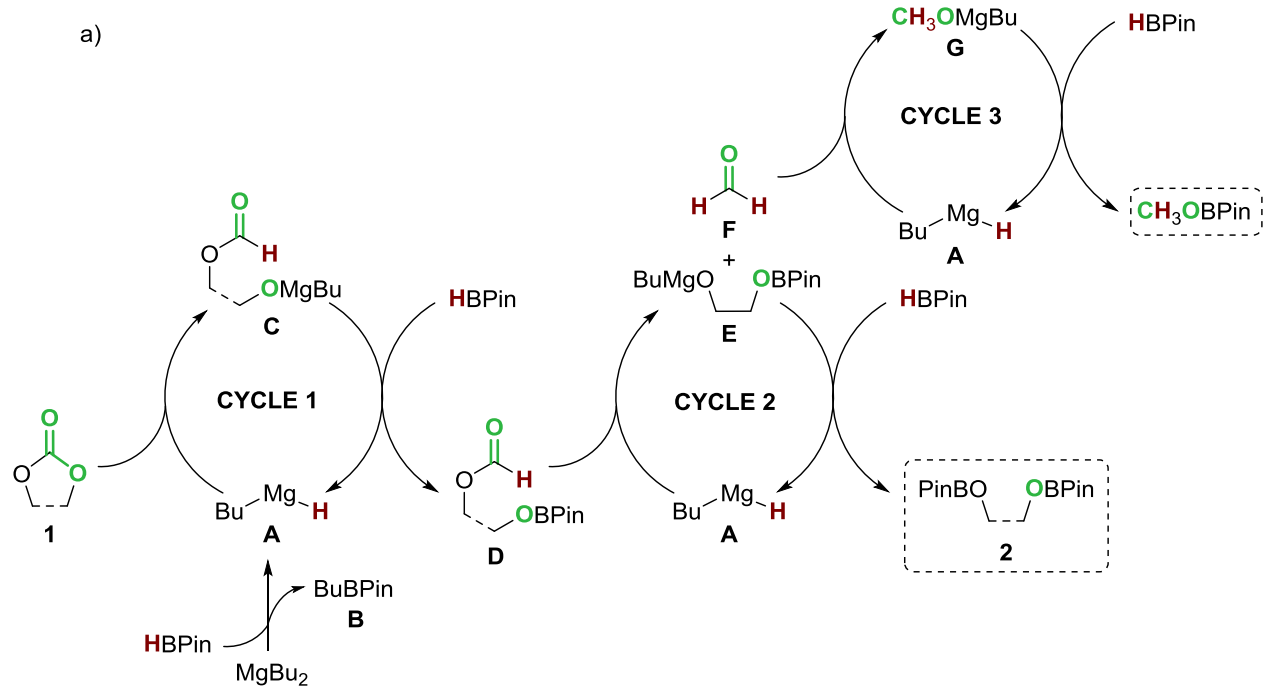

that the rate-limiting step is the first $\mathrm{Mg}-\mathrm{H}$ addition to the carbonate.

Based on the results and control experiments, we propose a mechanism for the magnesium-catalyzed hydroboration of carbonates (Scheme 5a). Reaction of $\mathrm{MgBu}_{2}$ with pinacolborane gives the active magnesium hydride species A. Carbonate $\mathbf{1}$ first reacts with magnesium hydride to form reactive magnesium alkoxide intermediate $\mathbf{C}$, which subsequently undergoes boron exchange with HBPin, regenerating the active species $\mathbf{A}$. Thus formed formate $\mathbf{D}$ enters the second catalytic cycle and reacts with the recovered active species $\mathbf{A}$, leading to the reduction of ester bond and formation of formaldehyde $\mathbf{F}$ and the corresponding intermediate $\mathbf{E}$. The second molecule of HBPin consumed in the reaction is necessary for the formation the final product 2 and the recovery of the active magnesium hydride species $\mathbf{A}$, which closes the catalytic cycle. Finally, formaldehyde $\mathbf{F}$ is reduced to form magnesium methoxide $\mathbf{G}$, which reacts with the third molecule of HBPin liberating MeOBPin. Given that $\beta$-diketiminate$\mathrm{MgBu}$ I catalyzes the reaction (Table 1, Entry 9), the formation of $\mathrm{LMgH}_{2}$ Bpin II in the reaction ${ }^{[12 \mathrm{~b}]}$ (Scheme $5 \mathrm{~b}$ ) cannot be fully excluded.

In summary, we report the first earth alkaline metalcatalyzed reduction of carbonates using a readily available magnesium catalyst. The new protocol shows a broad substrate scope, including various cyclic and linear carbonates. Furthermore, polycarbonates can be successfully recycled with the formation of the valuable diols and methanol. The procedure is characterized by its mild reaction conditions, fast reaction times, low catalyst loading, use of a readily available catalyst based on earth abundant magnesium, avoidance of costly ligands as well as broad scope and competes favorably with the transition metal catalyzed protocols. Mechanistic studies showed the formation of active $\mathrm{BuMgH}$, which acts as reducing catalyst and is involved in three sequential reduction cycles.

b)
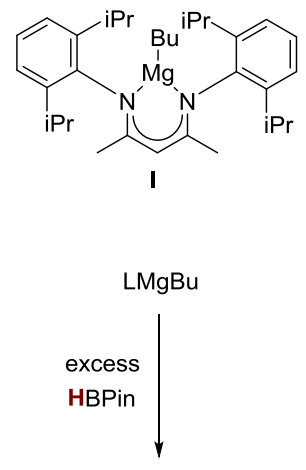

$\mathrm{LMgH}_{2}$ Bpin + BuBPin

II

Scheme 5. a) Proposed mechanism for $\mathrm{MgBu}_{2}$-catalyzed hydroboration of carbonates involving three sequential steps which require the $\mathrm{Mg}-\mathrm{H}$ species. b) Formation of the alternative $\mathrm{MgH}$ species when $\beta$-diketiminatomagnesium complex is used. 


\section{ASSOCIATED CONTENT}

The Supporting Information is available free of charge on the ACS Publications website.

Experimental procedures, characterization and NMR spectra (PDF).

\section{AUTHOR INFORMATION}

\section{Corresponding Author}

* Magnus Rueping : magnus.rueping@Kaust.edu.sa

\section{Notes}

The authors declare no competing financial interest.

\section{REFERENCES}

[1] a) Aresta, M. Carbon Dioxide as Chemical Feedstock Wiley-VCH: Weinheim, 2o10. b) Maeda, C.; Miyazaki, Y.; Ema, T. Recent Progress in Catalytic Conversions of Carbon Dioxide. Catal. Sci. Technol. 2014, 4, 1482-1497.

[2] For the reviews on transformation of epoxides to carbonates, see: a) North, M.; Pasquale, R.; Young, C. Synthesis of Cyclic Carbonates from Epoxides and $\mathrm{CO}_{2}$. Green Chem. 2010, 12, 1514-1539. b) He, Q.; O'Brien, J.; Kitselman, K.; Tompkins, L.; Curtis, G.; Kerton, F. Synthesis of Cyclic Carbonates from $\mathrm{CO}_{2}$ and Epoxides Using Ionic Liquids and Related Catalysts Including Choline Chloride-Metal Halide Mixtures. Catal. Sci. Technol. 2014, 4, 1513-1528. c) Martín, C.; Fiorani, G.; Kleij, A. Organic Carbonates as Solvents in Synthesis and Catalysis. ACS Catal. 2015, 5, 1353-1370. d) Comerford, J.; Ingram, I.; North, M.; Wu, X. Sustainable Metal-Based Catalysts for the Synthesis of $\mathrm{Cy}^{-}$ clic Carbonates Containing Five-Membered Rings. Green Chem. 2015, 17, 1966-1987. e) Cokoja, M.; Wilhelm, M.; Anthofer, M.; Herrmann, W.; Kühn, F. Synthesis of Cyclic Carbonates from Epoxides and Carbon Dioxide by Using Organocatalysts. ChemSusChem 2015, 8, 2436-2454.

[3] Schäffner, B.; Schäffner, F.; Verevkin, S. P.; Börner, A. Organic Carbonates as Solvents in Synthesis and Catalysis. Chem. Rev. 2010, 110, 4554-4581.

[4] For selected examples, see: a) Balaraman, E.; Gunanathan, C.; Zhang, J.; Shimon, L. J. W.; Milstein, D. Efficient Hydrogenation of Organic Carbonates, Carbamates and Formates Indicates Alternative Routes to Methanol Based on $\mathrm{CO}_{2}$ and CO. Nat. Chem. 2o11, 3, 6o9-614. b) Han, Z.; Rong, L.; Wu, J.; Zhang, L.; Wang, Z.; Ding, K. Catalytic Hydrogenation of Cyclic Carbonates: a Practical Approach from $\mathrm{CO}_{2}$ and Epoxides to Methanol and Diols. Angew. Chem. Int. Ed. 2012, 51, 13041-13045; Angew. Chem. 2012, 124, 13218-13222. c) Kim, S.; Hong, S. Transfer Hydrogenation of Organic Formates and Cyclic Carbonates: An Alternative Route to Methanol from Carbon Dioxide. ACS Catal. 2014, 4, 3630-3636. d) vom Stein, T.; Meuresch, M.; Limper, D.; Schmitz, M.; Hölscher, M.; Coetzee, J.; ColeHamilton, D.; Klankermayer, J.; Leitner, W. Highly Versatile Catalytic Hydrogenation of Carboxylic and Carbonic Acid Derivatives using a Ru-Triphos Complex: Molecular Control over Selectivity and Substrate Scope J. Am. Chem. Soc. 2014, 136, 13217-13225. e) Zubar, V.; Lebedev, Y.; Azofra, L.; Cavallo, L.; El-Sepelgy, O.; Rueping, M. Hydrogenation of $\mathrm{CO}_{2}$-Derived Carbonates and Polycarbonates to Methanol and Diols by Metal-Ligand Cooperative Manganese Catalysis. Angew. Chem. Int. Ed. 2018, 57, 1343913443. f) Kumar, A.; Janes, T.; Espinosa-Jalapa, N.; Milstein, D. Manganese Catalyzed Hydrogenation of Organic Car- bonates to Methanol and Alcohols. Angew. Chem. Int. Ed. 2018, 57, 12076-12080; Angew. Chem. 2018, 130, 12252-12256. g) Kaithal, A.; Hölscher, M.; Leitner, W. Catalytic Hydrogenation of Cyclic Carbonates using Manganese Complexes. Angew. Chem. Int. Ed. 2018, 57, 13449-13453; Angew. Chem. 2018, 130, 13637-13641.

[5] Erken, C.; Kaithal, A.; Sen, S.; Weyhermüller, T.; Hölscher, M.; Werlé, C.; Leitner, W. Manganese-Catalyzed Hydroboration of Carbon Dioxide and Other Challenging Carbonyl Groups. Nat. Commun. 2018, 9, 4521.

[6] a) Hill, M.; Liptrot, D.; Weetman, C. Alkaline Earths as Main Group Reagents in Molecular Catalysis. Chem. Soc. Rev. 2016, 45, 972-988. b) Rochat, R.; Lopez, M.; Tsurugi, H.; Mashima, K. Recent Developments in Homogeneous Organomagnesium Catalysis. ChemCatChem 2016, 8, 1020.

[7] For illustrative examples using magnesium organometallics for deprotonation/metalation reactions, see: a) Dong, Z.; Clososki, G. C.; Wunderlich, S. H.; Unsinn, A.; Li, J.; Knochel, P. Direct Zincation of Functionalized Aromatics and Heterocycles by Using a Magnesium Base in the Presence of $\mathrm{ZnCl}_{2}$. Chem. Eur. J. 2009, 15, 457-468. b) Piller, F. M.; Bresser, T.; Fischer, M. K. R.; Knochel, P. Preparation of Functionalized Cyclic Enol Phosphates by Halogen-Magnesium Exchange and Directed Deprotonation Reactions. J. Org. Chem. 2010, 75, 4365-4375. c) Haag, B.; Mosrin, M.; Ila, H.; Malakhov, V.; Knochel, P. Regio- and Chemoselective Metalation of Arenes and Heteroarenes Using Hindered Metal Amide Bases. Angew. Chem. Int. Ed. 2011, 50, 9794-9824; Angew. Chem. 2011, 123, 9968-9999. d) Benischke, A. D.; Ellwart, M.; Becker, M. R.; Knochel, P. Polyfunctional Zinc and Magnesium Organometallics for Organic Synthesis: Some Perspectives. Synthesis 2016, 48, 1101-1107.

[8] For recent reviews on the use of organomagnesium hydride complexes as catalysts, see: a) Crimmin, M. R.; Hill, M. S. Homogeneous Catalysis with Organometallic Complexes of Group 2. Top. Organomet. Chem. 2013, 45, 191-241. b) Revunova, K.; Nikonov, G. I. Main Group Catalysed Reduction of Unsaturated Bbonds. Dalton Trans. 2015, 44, 840-866. c) Pellissier, H. Enantioselective MagnesiumCatalyzed Transformations. Org. Biomol. Chem. 2017, 15, $4750-4782$.

[9] For illustrative examples of the $\beta$-diketiminatemagnesium complexes as catalyst precursors, see: a) Green, S.; Jones, C.; Stasch, A. Stable Adducts of a Dimeric Magnesium(I) Compound. Angew. Chem. Int. Ed. 2oo8, 47, 9079-9083. b) Arrowsmith, M.; Hill, M.; Hadlington, T.; Kociok-Köhn, G.; Weetman, C. Magnesium-Catalyzed Hydroboration of Pyridines. Organometallics 2011, 30, 5556-5559. c) Harder, S.; Spielmannb, J.; Intemann J. Synthesis and Thermal Decomposition of a Pyridylene-Bridged Bis- $\beta$-diketiminate Magnesium Hydride Cluster. Dalton Trans. 2014, 43, 14284-14290. d) Garcia, L.; Dinoi, C.; Mahon, M.; Maron, L.; Hill, M. Magnesium Hydride Alkene Insertion and Catalytic Hydrosilylation. Chem. Sci. 2019, 10, 8108-8118.

[10] $\beta$-Diketiminate-magnesium complexes have also been succesfully applied in $\mathrm{C}-\mathrm{H}$ and $\mathrm{C}-\mathrm{F}$ activations. For the leading examples see: a) Davin, L.; McLellan, R.; Kennedy, A. R.; Hevia, E. Ligand-Induced Reactivity of $\beta$ Diketiminate Magnesium Complexes for Regioselective Functionalization of Fluoroarenes via $\mathrm{C}-\mathrm{H}$ or $\mathrm{C}-\mathrm{F}$ Bond Activations. Chem. Commun. 2017, 53, 11650-11653. b) Davin, L.; McLellan, R.; Hernán-Gómez, A.; Clegg, W.; Kennedy, A. R.; Mertens, M.; Stepek, I.; Hevia, E. Regioselective Magnesiation of N-Heterocyclic Molecules: 
Securing Insecure Cyclic Anions by a $\beta$-DiketiminateMagnesium Clamp. Chem. Commun. 2017, 53, 3653-3656.

[11] For $\mathrm{MgBu}_{2}$-catalyzed hydroborations, see: a) Magre, M.; Maity, B.; Falconnet, A.; Cavallo, L.; Rueping, M. Magnesium-Catalyzed Hydroboration of Terminal and Internal Alkynes. Angew. Chem. Int. Ed. 2019, 58, 7025-7029. b) Jang, Y. K.; Magre, M.; Rueping, M. Chemoselective Luche-Type Reduction of $\alpha, \beta$-Unsaturated Ketones by Magnesium Catalysis. Org. Lett. 2019, 21, 8349-8352.

[12] For leading examples of $\beta$-diketiminate-magnesium complexes in hydroboration reactions, see: ref. $9 \mathrm{~b}$ and a) Arrowsmith, M.; Hadlington, T.; Hill, M.; Kociok-Köhn, G. Magnesium-Catalysed Hydroboration of Aldehydes and Ketones. Chem. Commun. 2012, 48, 4567-4569. b) Mukherjee, D.; Ellernm A.; Sadow, A. Magnesium-Catalyzed Hydroboration of Esters: Evidence for a New Zwitterionic Mechanism. Chem. Sci. 2014, 5, 959-964. c) Anker, M.; Arrowsmith, M.; Bellham, P.; Hill, M.; Kociok-Köhn, G.; Liptrot, D.; Mahona, M.; Weetman, C. Selective Reduction of $\mathrm{CO}_{2}$ to a Methanol Equivalent by $\mathrm{B}\left(\mathrm{C}_{6} \mathrm{~F}_{5}\right)_{3}$-Activated Alkaline Earth Catalysis. Chem. Sci. 2014, 5, 2826-2830. d) Li, J.; Luo, M.; Sheng, X.; Hua, H.; Yao, W.; Pullarkat, S.; Xu, L.; Ma, M. Unsymmetrical $\beta$-Diketiminate Magnesium(I) Complexes: Syntheses and Application in Catalytic Hydroboration of Alkyne, Nitrile and Carbonyl Compounds. Org. Chem. Front. 2018, 5, 3538-3547. e) Yadav, S.; Dixit, R.; Bisai, M.; Vanka, K.; Sen, S. Alkaline Earth Metal Compounds of Methylpyridinato $\beta$-Diketiminate Ligands and Their Catalytic Application in Hydroboration of Aldehydes and Ketones. Organometallics 2018, 37, 4576-4584.

[13] For various magnesium complexes used in hydroboration reactions, see: a) Mukherjee, D.; Shirase, S.; Spaniol, T.; Mashima, K.; Okuda, J. Magnesium Hydridotriphenylborate $\left[\mathrm{Mg}(\mathrm{thf})_{6}\right]\left[\mathrm{HBPh}_{3}\right]_{2}:$ a Versatile Hydroboration Catalyst. Chem. Commun. 2016, 52, 1315513158. b) Manna, K.; Ji, P.; Greene, F.; Lin, W. MetalOrganic Framework Nodes Support Single-Site Magnesium-Alkyl Catalysts for Hydroboration and Hydroamination Reactions. J. Am. Chem. Soc. 2016, 138, 7488-7491. c) Ma, M.; Li, J.; Shen, X.; Yu, Z.; Yao, W.; Pullarkat, S. Sterically Bulky Amido Magnesium Methyl Complexes: Syntheses, Structures and Catalysis. RSC Adv.
2017, 7, 45401-45407. d) Rauch, M.; Ruccolo, S.; Parkin, G. Synthesis, Structure, and Reactivity of a Terminal Magnesium Hydride Compound with a Carbatrane Motif, $\left[\right.$ Tism $\left.^{\text {PriBenz }}\right] \mathrm{MgH}:$ A Multifunctional Catalyst for Hydrosilylation and Hydroboration. J. Am. Chem. Soc. 2017, 139, 13264-13267. e) Lampland, N.; Hovey, M.; Mukherjee, D.; Sadow, A. Magnesium-Catalyzed Mild Reduction of Tertiary and Secondary Amides to Amines. ACS Catal. 2015, 5, 4219-4226. f) Barman, M.; Baishya, A.; Nembenna, S. Magnesium Amide Catalyzed Selective Hydroboration of Esters. Dalton Trans. 2017, 46, 4152-4156. g) Falconnet, A.; Magre, M.; Maity, B.; Cavallo, L.; Rueping, M. Asymmetric Magnesium-Catalyzed Hydroboration by Metal-Ligand Cooperative Catalysis. Angew. Chem. Int. Ed. 2019, DOI: 10.1002/anie.201908012.

[14] For the formation of $\mathrm{BuMgH}$, see: ref. 11a. For the formation of magnesium hydride complexes using HBPin, see: ref. 11-13. For the formation of $\mathrm{Mg}-\mathrm{H}$ complexes using hydrosilanes, see: ref. 9d and a) Dunne, J.; Neal, S.; Engelkemier, J.; Ellern, A.; Sadow, A. Tris(oxazolinyl)boratomagnesium-Catalyzed CrossDehydrocoupling of Organosilanes with Amines, Hydrazine, and Ammonia. J. Am. Chem. Soc. 2011, 133, 1678216785. b) Hill, M.; Liptrot, D.; MacDougall, D.; Mahon M.; Robinson, T. Hetero-Dehydrocoupling of Silanes and Amines by Heavier Alkaline Earth Catalysis. Chem. Sci. 2013, 4, 4212-4222. c) Baishya, A.; Peddarao, T.; Nembenna, S. Organomagnesium Amide Catalyzed Crossdehydrocoupling of Organosilanes with Amines. Dalton Trans. 2017, 46, 5880-5887. d) Rauch, M.; Parkin, G. Zinc and Magnesium Catalysts for the Hydrosilylation of Carbon Dioxide. J. Am. Chem. Soc. 2017, 139, 18162-18165.

[15] In some protocols for the transition metal-catalyzed direct hydrogenation of organic carbonates, the scope is limited only to cyclic carbonates. See for instance: ref. 4a, 4e, and $4 \mathrm{~g}$.

[16] For the detailed experimental procedures, see Supporting Information.

[17] Magnesium complexes have been successfully employed for hydroboration of $\mathrm{CO}_{2}$. For more detailed information, see: ref. $11 g$ and $12 a$.

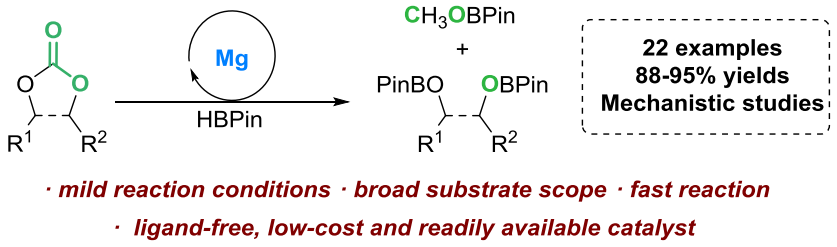

